\title{
Declaration of Madrid: position statement on the preparation of critical care nurses (version 2)
}

Ged Williams, RN, RM, Crit. Care Cert., Grad. Cert. PSM, Bach. App. Sc. (Adv. Nursing), Grad. Cert Law, LLM (QUT), MHA (UNSW), FRCNA, FCN NSW, FACHSE, Chair, the World Federation of Critical Care Nurses

E-mail: ged.williams@maroondah.org.au

\section{BACKGROUND}

At the $6^{\text {th }}$ World Congress on Intensive Care and Critical Care in Madrid, Spain in 1993, the World Federation of Societies of Intensive Care and Critical Care Medicine endorsed what has become known as the Declaration of Madrid on the preparation of critical care nurses (WFSICCM, 1993).

In May 2003, the World Federation of Critical Care Nurses (WFCCN) undertook a review of the Declaration of Madrid, along with recommendations from the Australian College of Critical Care Nurses position statement on critical care nursing education (Underwood et al., 1999) and other similar documents from member associations. The current position statement aims to inform and assist critical care nursing associations, health services, educational facilities and other interested parties about the development and provision of critical care nursing education.

The current draft position statement aims to canvass world-wide comment and opinion on the appropriateness and acceptability of the principles and recommendations contained within it.

Final ratification of the position statement will occur at the 9th World Congress on Intensive Care and Critical Care in Buenos Aires, Argentina, in August 2005. Comments and questions on this current draft should be directed to the author at the above e-mail address.

\section{PREAMBLE}

Critical or intensive care is a complex speciality developed to serve the delicate health care needs of patients (and families) with actual or potential life threatening conditions.

The role of the critical care nurse is essential to the multidisciplinary team needed to provide care to critically ill patients. By enhancing the delivery of a holistic, patient-centred approach in a highly technical environment, the critical care nurse brings to this team a unique combination of knowledge and caring. To fulfil this role, nurses require appropriate specialised knowledge and skills not typically included in the basic nursing programmes of most countries.

Governmental, professional and educational bodies governing the practice of nursing must recognise the vital importance of specialised preparation for critical care nurses in ensuring the health of their communities. This declaration presents guidelines universally accepted by critical care professionals, which may be adapted to meet the educational and health care requirements of a particular country or jurisdiction.

\section{CENTRAL PRINCIPLES}

1. Patients and families have the right to receive individualised critical care from qualified professional nurses.

2. Critical care nurses must possess appropriate knowledge and skills to effectively respond to the needs of patients, to the demands of society, and to the challenges of advancing technology.

3. When a basic nursing education programme does not include the specialised knowledge and skills needed, these must be provided to nurses who will take care of critically ill patients and their families.

4. Nurses with specialised knowledge and expertise in the provision of care to critically ill patients should play an integral part in the education of critical care nurses, even when a multidisciplinary educational approach is used.

5. The preparation of critical care nurses must be based on the most currently available information and research.

\section{RECOMMENDATIONS FOR CRITICAL CARE NURSING EDUCATION}

The WFCCN believes that critically ill patients have very special needs and must be cared for by nurses with specialist skills, knowledge and attitudes.

The following recommendations have been adopted to represent universal principles to help guide health services, educational facilities and critical care nursing organisations in the development of appropriate educational programmes for nurses who are required to care for critically ill patients and their families:

1. As a minimum, the critical care dimensions of the following topics should be included in programmes to prepare critical care nurses. The categories are not listed in order of importance:

* Anatomy and physiology

* Pathophysiology

* Pharmacology

* Clinical assessment

* Illnesses and alterations of vital body functions

* Plans of care and nursing interventions

* Medical indications and prescriptions with resulting nursing care responsibilities

* Psychosocial aspects (including cultural and spiritual needs)

* Technology applications 
Patient and family education

Legal and ethical issues

Professional nursing issues and roles in critical care

Use of current research findings; evidence-based multidisciplinary care.

Programmes preparing critical care nurses to function at a specialist level of practice should be provided at a post-registration level and conducted by a higher education provider (for example, a university or equivalent).

3. The curricula of critical care nursing post-registration courses must provide an appropriate mix of theoretical and clinical experience to prepare nurses to meet the challenges of clinical practice effectively.

4. WFCCN recommends that national critical care nursing associations establish agreed standards for specialist critical care nursing to be used as a framework for both critical care curriculum development and assessment of clinical practice.

5. Post-registration courses for critical care nurses must provide a balance between clinically-oriented content and broader generic content that enables the specialist nurse to contribute to the profession through processes such as research, practice development and leadership.

6. Close collaboration between the healthcare and higher education sectors is important so that post-registration critical care nursing education can be provided at a standard that meets the expectations of both sectors.

7. Graduates of post-registration courses in critical care must be able to demonstrate clinical competence as well as a sound theoretical knowledge base. A strong emphasis on the application of theory to practice and the assessment of clinical competence should be integral components of post-registration critical care courses.

8. The provision of appropriate clinical experience to facilitate the development of clinical competence should be a collaborative responsibility between education and health care providers. Critical care students should have access to support and guidance from appropriately experienced staff, such as clinical teachers and nurse preceptors.

9. Clinical teachers and nurse preceptors for post-registration critical care students should be appropriately supported in their roles by both education and healthcare providers.

10. Critical care education providers should have policies and processes in place for recognition of prior learning and alternative entry pathways into formal postregistration specialist courses to create a more flexible yet consistent means for students to attain recognition of competence.

11. Healthcare and higher education providers need to establish strategies to help reduce the financial burden faced by nurses undertaking post-registration critical care courses.

12. Education providers must implement educational strategies to facilitate access to post-registration courses for critical care nurses from a range of geographical locations.

13. Innovative strategies need to be implemented to address the deficit of qualified critical care nurses, rather than resorting to short training courses to resolve the problem. Such strategies could include comprehensive critical care workforce planning, innovative retention strategies, refresher 'training', professional development programmes and the provision of greater support for nurses undertaking post-registration critical care courses.

14. Providers of short critical care training courses should seek credit transfer (recognition of prior learning) within the higher education sector for nurses completing these courses.

\section{REFERENCES}

Underwood M, Elliott D, Aitken L, Austen D, Currey J, Field T, Grech C, Kiegaldie D, Pittard M \& Worral-Carter L. (1999) Position statement on postgraduate critical care nursing education. Australian Critical Care 12 (4), 160-164.

World Federation of Societies of Intensive and Critical Care Medicine.

(1993) Declaration of Madrid on the preparation of critical care nurses. Australian Critical Care 6 (2), 24. 